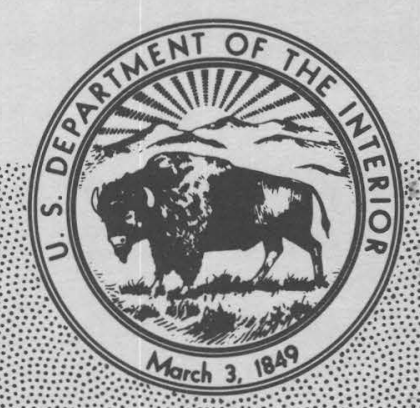

Principles of a

Resource/Reserve Classification

For Minerals 



\section{Principles of a \\ Resource/Reserve Classification For Minerals}

By the U.S. Bureau of Mines and the U.S. Geological Survey

GEOLOGICAL SURVEY CIRCULAR 831

$A$ revision of the classification system

published as U.S. Geological Survey Bulletin 1450-A 


\section{United States Department of the Interior CECIL D. ANDRUS, Secretary}

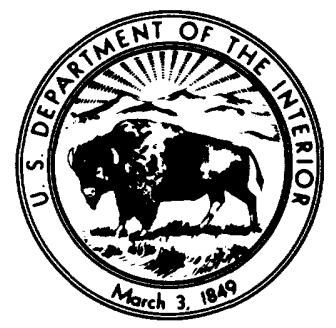

Geological Survey

H. William Menard, Director

Library of Congress Cataloging in Publication Data

United States. Bureau of Mines.

Principles of a resource/reserve classification for minerals.

(Geological Survey circular ; 831)

Edition for 1976 published under title: Principles of the mineral resource classification system of the U.S. Bureau of Mines and U.S. Geological Survey.

Bibliography: $p$.

1. Mines and mineral resources-United States-Classification. I. United States. Geological Survey.

II. Title. III. Series: United States. Geological Survey. Circular ; 831. QE75.C5 no. 831 [TN153] 557.3s [553'.01'2] 80-607901. 


\section{CONTENTS}

Introduction

Page

Resource/reserve definitions -

1

1

\section{ILLUSTRATIONS}

FIGURE 1. Diagrammatic illustration of major elements of mineral-resource classification

2. Diagrammatic illustration of reserve base and inferred reserve base classification categories 


\title{
Principles of a Resource/Reserve Classification for Minerals
}

\author{
By the U.S. BuREAu OF MineS and the U.S. GeologiCal SURVEY
}

\section{INTRODUCTION}

Through the years, geologists, mining engineers, and others operating in the minerals field have used various terms to describe and classify mineral resources, which as defined herein include energy materials. Some of these terms have gained wide use and acceptance, although they are not always used with precisely the same meaning.

Staff members of the U.S. Bureau of Mines and the U.S. Geological Survey collect information about the quantity and quality of all mineral resources, but from different perspectives and with different purposes. In 1976, a team of staff members from both agencies developed a common classification and nomenclature, which was published as U.S. Geological Survey Bulletin 1450-A - "Principles of the Mineral Resource Classification System of the U.S. Bureau of Mines and U.S. Geological Survey." Experience with this resource classification system showed that some changes were necessary in order to make it more workable in practice and more useful in long-term planning. Therefore, representatives of the U.S. Geological Survey and the U.S. Bureau of Mines collaborated to revise Bulletin 1450-A.

Long-term public and commercial planning must be based on the probability of discovering new deposits, on developing economic extraction processes for currently unworkable deposits, and on knowing which resources are immediately available. Thus, resources must be continuously reassessed in the light of new geologic knowledge, of progress in science and technology, and of shifts in economic and political conditions. To best serve these planning needs, known resources should be classified from two standpoints: (1) purely geologic or physical/chemical characteristics-such as grade, quality, tonnage, thickness, and depth-of the material in place: and (2) profitability analyses based on costs of extracting and marketing the material in a given economy at a given time. The former constitutes important objective scientific information of the resource and a relatively unchanging foundation upon which the latter more variable economic delineation can be based.

The revised classification system, designed generally for all mineral materials, is shown graphically in figures 1 and 2 (see page 5); its components and their usage are described in the text. The classification of mineral and energy resources is necessarily arbitrary, because definitional criteria do not always coincide with natural boundaries. The system can be used to report the status of mineral and energy-fuel resources for the $\mathrm{Na}$ tion or for specific areas.

\section{RESOURCE/RESERVE DEFINITIONS}

A dictionary definition of resource, "something in reserve or ready if needed," has been adapted for mineral and energy resources to comprise all materials, including those only surmised to exist, that have present or anticipated future value.

Resource. - A concentration of naturally occurring solid, liquid, or gaseous material in or on the Earth's crust in such form and amount that economic extraction of a commodity from the concentration is currently or potentially feasible.

Original Resource.-The amount of a resource before production.

Identified Resources. - Resources whose location, grade, quality, and quantity are known or estimated from specific geologic evidence. Identified resources include economic, marginally economic, and subeconomic components. To reflect varying degrees of geologic 
(Identified Resources-Continued)

certainty, these economic divisions can be subdivided into measured, indicated, and inferred. ${ }^{1}$

Demonstrated. - A term for the sum of measured plus indicated.

Measured.-Quantity is computed from dimensions revealed in outcrops, trenches, workings, or drill holes; grade and(or) quality are computed from the results of detailed sampling. The sites for inspection, sampling, and measurement are spaced so closely and the geologic character is so well defined that size, shape, depth, and mineral content of the resource are well established.

Indicated.-Quantity and grade and(or) quality are computed from information similar to that used for measured resources, but the sites for inspection, sampling, and measurement are farther apart or are otherwise less adequately spaced. The degree of assurance, although lower than that for measured resources, is high enough to assume continuity between points of observation.

Inferred.-Estimates are based on an assumed continuity beyond measured and(or) indicated resources, for which there is geologic evidence. Inferred resources may or may not be supported by samples or measurements.

Reserve Base. - That part of an identified resource that meets specified minimum physical and chemical criteria related to current mining and production practices, including those for grade, quality, thickness, and depth. The reserve base is the in-place demonstrated (measured plus indicated) resource from which reserves are estimated. It may encompass those parts of the resources that have a reasonable potential for becoming economically available within planning horizons beyond those that assume proven technology and current economics. The reserve base includes those

1The terms "proved," "probable," and "possible", which are commonly used by in. dustry in economic evaluations of ore or mineral fuels in specific deposits or districts, have been loosely interchanged with the terms measured, indicated, and inferred. The former terms are not a part of this classification system.
(Reserve Base-Continued)

resources that are currently economic (reserves), marginally economic (marginal reserves), and some of those that are currently subeconomic (subeconomic resources). The term "geologic reserve" has been applied by others generally to the reserve-base category, but it also may include the inferred-reservebase category; it is not a part of this classification system.

Inferred Reserve Base.-The in-place part of an identified resource from which inferred reserves are estimated. Quantitative estimates are based largely on knowledge of the geologic character of a deposit and for which there may be no samples or measurements. The estimates are based on an assumed continuity beyond the reserve base, for which there is geologic evidence.

Reserves.-That part of the reserve base which could be economically extracted or produced at the time of determination. The term reserves need not signify that extraction facilities are in place and operative. Reserves include only recoverable materials; thus, terms such as "extractable reserves" and "recoverable reserves" are redundant and are not a part of this classification system.

Marginal Reserves. - That part of the reserve base which, at the time of determination, borders on being economically producible. Its essential characteristic is economic uncertainty. Included are resources that would be producible, given postulated changes in economic or technologic factors.

Economic. - This term implies that profitable extraction or production under defined investment assumptions has been established, analytically demonstrated, or assumed with reasonable certainty.

Subeconomic Resources. - The part of identified resources that does not meet the economic criteria of reserves and marginal reserves.

Undiscovered Resources. - Resources, the existence of which are only postulated, comprising deposits that are separate from identified resources. Undiscovered resources may be postulated in deposits of such grade and physical location as to render them economic, marginally economic, or subeconomic. To reflect varying degrees of geologic certainty, 
(Undiscovered Resources-Continued)

undiscovered resources may be divided into two parts:

Hypothetical Resources. - Undiscovered resources that are similar to known mineral bodies and that may be reasonably expected to exist in the same producing district or region under analogous geologic conditions. If exploration confirms their existence and reveals enough information about their quality, grade, and quantity, they will be reclassified as identified resources.

Speculative Resources. - Undiscovered resources that may occur either in known types of deposits in favorable geologic settings where mineral discoveries have not been made, or in types of deposits as yet unrecognized for their economic potential. If exploration confirms their existence and reveals enough information about their quantity, grade, and quality, they will be reclassified as identified resources.

Restricted Resources/Reserves. - That part of any resource/reserve category that is restricted from extraction by laws or regulations. For example, restricted reserves meet all the requirements of reserves except that they are restricted from extraction by laws or regulations.

\section{GUIDELINES FOR CLASSIFICATION OF MINERAL RESOURCES}

1. All naturally occurring metals, nonmetals, and fossil fuels in sufficient concentration can be classified in one or more of the categories.

2. Where the term reserves is used alone, without a modifying adjective such as indicated, marginal, or inferred, it is to be considered synonymous with the demonstrated-economic category, as shown in figure 1.

3. Definitions of resource categories can be modified for a particular commodity in order to conform with accepted usage involving special geological and engineering characteristics. Such modified definitions for particular commodities will be given in forthcoming government publications.

4. Quantities, qualities, and grades may be expressed in different terms and units to suit different purposes, but usage must be clearly stated and defined.
5. The geographic area to which any resource/reserve estimate refers must be defined.

6. All estimates must show a date and author.

7. The reserve base is an encompassing resource category delineated by physical and chemical criteria. A major purpose for its recognition and appraisal is to aid in long-range public and commercial planning. For most mineral commodities, different grades and tonnages, or other appropriate resource parameters, can be specified for any given deposit or area, or for the Nation, depending on the specific objectives of the estimators; therefore, the position of the lower boundary of the reserve base, which extends into the subeconomic category, is variable, depending on those objectives. The intention is to define a quantity of in-place material, any part of which may become economic, depending on the extraction plans and economic assumptions finally used. When those criteria are determined, the initial reserve-base estimate will be divided into three component parts: reserves, marginal reserves, and a remnant of subeconomic resources. For the purpose of Federal commodity assessment, criteria for the reserve base will be established for each commodity.

8. Undiscovered resources may be divided in accordance with the definitions of hypothetical and speculative resources, or they may be divided in terms of relative probability of occurrence.

9. Inferred reserves and the inferred reserve base are postulated extensions of reserves and of the reserve base. They are identified resources quantified with a relatively low degree of certainty. Postulated quantities of resources not based on reserve/reserve-base extensions, but rather on geologic inference alone, should be classified as undiscovered.

10. Locally, limited quantities of materials may be produced, even though economic analysis has indicated that the deposit would be too thin, too low grade, or too deep to be classified as a reserve. This situation might arise when the production facilities are already established or when favorable local circumstances make it possible to produce material that elsewhere could not be extracted profitably. Where such production is taking place, the quantity of in-place material shall be included in the reserve base, and the quantity that is potentially producible shall be included as a reserve. The profitable production of such materials locally, however, should not be used as a rationale in other 
areas for classifying as reserves, those materials that are similar in thickness, quality, and depth.

11. Resources classified as reserves must be considered economically producible at the time of classification. Conversely, material not currently producible at a profit cannot be classified as reserves. There are situations, however, in which mining plans are being made, lands are being acquired, or mines and plants are being constructed to produce materials that do not meet economic criteria for reserve classification under current costs and prices, but would do so under reasonable future expectations. For some other materials, economic producibility is uncertain only for lack of detailed engineering assessment. The marginalreserves category applies to both situations. When economic production appears certain for all or some of a marginal reserve, it will be reclassified as reserves.

12. Materials that are too low grade or for other reasons are not considered potentially economic, in the same sense as the defined resource, may be recognized and their magnitude estimated, but they are not classified as resources. A separate category, labeled other occurrences, is included in figures 1 and 2.

13. In figure 1 , the boundary between subeconomic and other occurrences is limited by the concept of current or potential feasibility of economic production, which is required by the definition of a resource. The boundary is obviously uncertain, but limits may be specified in terms of grade, quality, thickness, depth, percent extractable, or other economic-feasibility variables.

14. Varieties of mineral or energy commodities, such as bituminous coal as distinct from lignite, may be separately quantified when they have different characteristics or uses.

15. The amount of past cumulative production is not, by definition, a part of the resource. Nevertheless, a knowledge of what has been produced is important to an understanding of current resources, in terms of both the amount of past production and the amount of residual or remaining in-place resource. A separate space for cumulative production is shown in figure 1. Residual material left in the ground during current or future extraction should be recorded in the resource category appropriate to its economic-recovery potential.

16. In classifying reserves and resources, it is necessary to recognize that some minerals derive their economic viability from their coproduct or byproduct relationships with other minerals. Such relationships must be clearly explained in footnotes or in an accompanying text.

17. Considerations other than economic and geologic, including legal, regulatory, environmental, and political, may restrict or prohibit the use of all or part of a deposit. Reserve and resource quantities known to be restricted should be recorded in the appropriate classification category; the quantity restricted and the reason for the restriction should be noted.

18. The classification system includes more divisions than will commonly be reported or for which data are available. Where appropriate, divisions may be aggregated or omitted.

19. The data upon which resource estimates are based and the methods by which they are derived are to be documented and preserved. 
RESOURCES OF (commodity name)

[A part of reserves or any resource category may be restricted from extraction by laws or regulations (see text)]

AREA: (mine, district, field, State, etc.) UNITS: (tons, barrels, ounces, etc.)

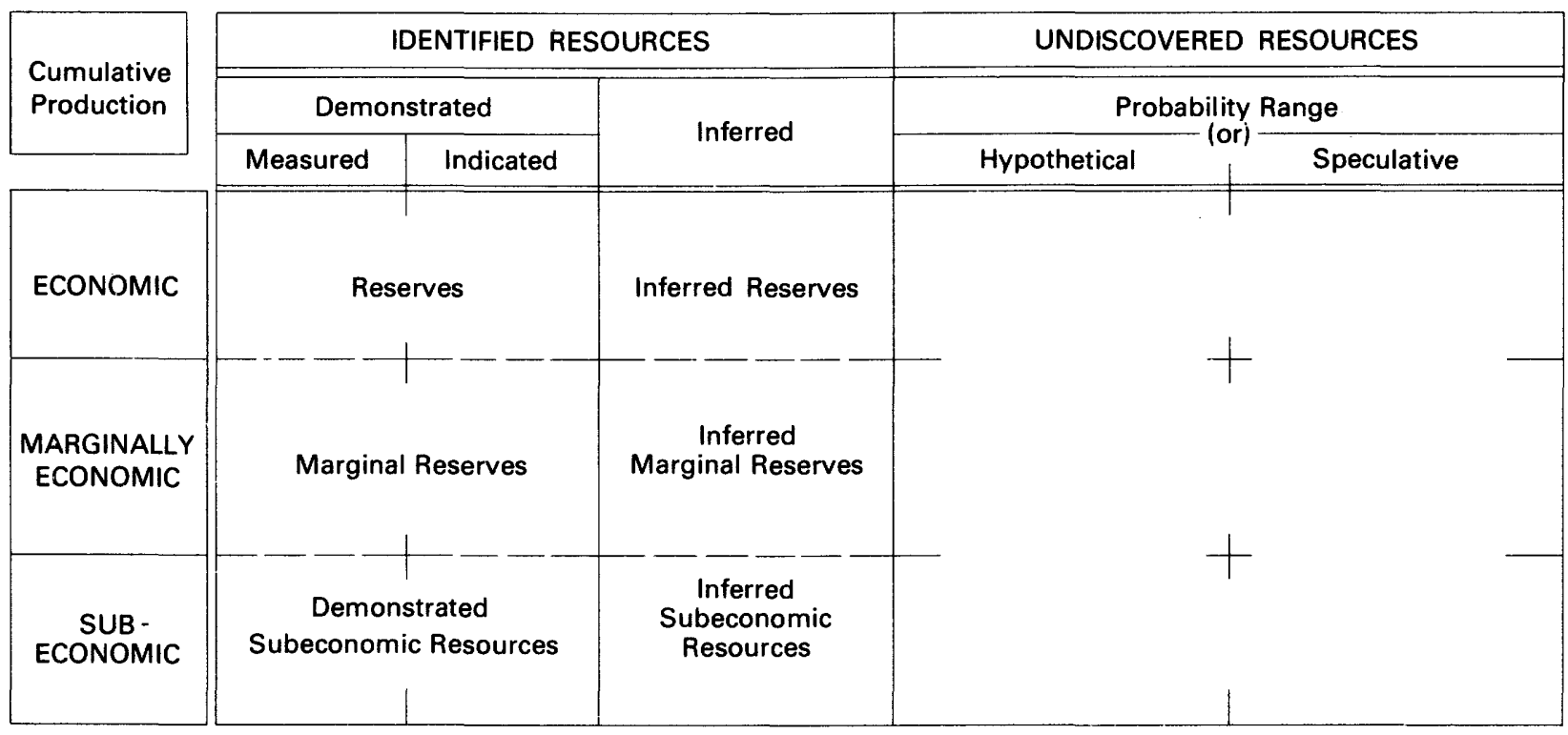

Other Occurrences
Includes nonconventional and low-grade materials

Author:

Date:

FIGURE 1. - Major elements of mineral-resource classification, excluding reserve base and inferred reserve base.

$$
\text { RESOURCES OF (commodity name) }
$$

[A part of reserves or any resource category may be restricted from extraction by laws or regulations (see text)] AREA: (mine, district, field, State, etc.) UNITS: (tons, barrels, ounces, etc.)

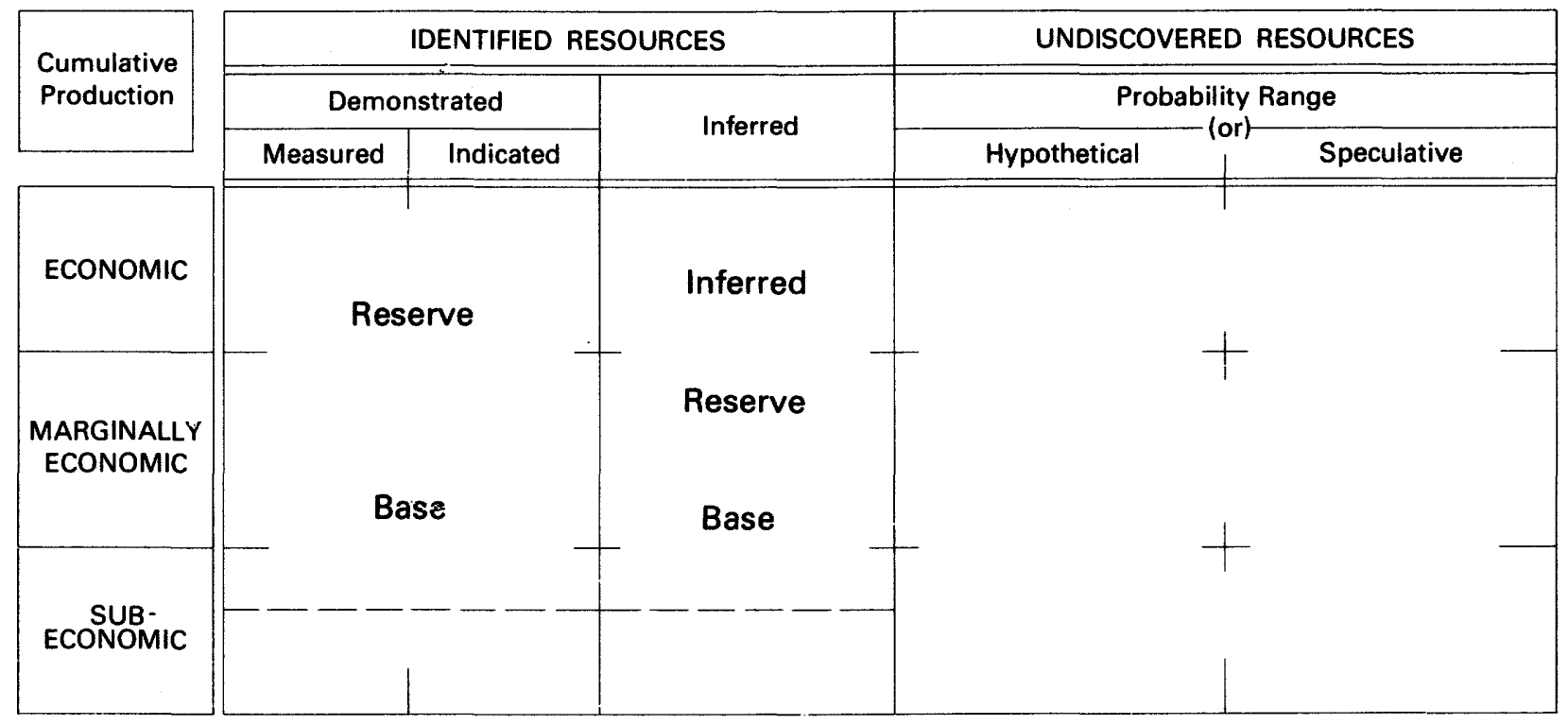

Other Occurrences
Includes nonconventional and low-grade materials

Date:

FIGURE 2.-Reserve base and inferred reserve base classification categories. 

f

5

$\frac{\overline{3}}{\overline{0}}$

ర్ర

플

受

$\frac{5}{5}$

o

8

$\S$

旁

ํㅡㅅ

톨

E 